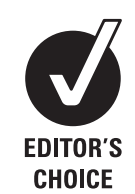

${ }^{1}$ Department of Ophthalmology, Erasmus University Medical Center, Rotterdam, The Netherlands

${ }^{2}$ Hogeschool Utrecht, University of Applied Sciences, Utrecht, The Netherlands

\section{Correspondence to} Dr R C W Wolfs, Erasmus University Medical Center, Department of Ophthalmology, 3000-CA Rotterdam, The Netherlands;

r.wolfs@erasmusmc.nl

Accepted 13 June 2010 Published Online First 6 August 2010

\title{
Prediction error and myopic shift after intraocular lens implantation in paediatric cataract patients
}

\author{
N E D Hoevenaars, ${ }^{1}$ J R Polling, ${ }^{1,2}$ R C W Wolfs ${ }^{1}$
}

\author{
ABSTRACT \\ Aim To determine the amount of myopic shift in children \\ after cataract surgery with intraocular lens (IOL) \\ implantation and to evaluate success in achieving the \\ target refraction.
}

Methods The children were assigned into three groups depending on age at time of surgery: Group $A$, 0-1 years old; Group B, 1-7 years old; Group C, 7-18 years old. Multiple regression analysis was used to create a formula for expected myopic shift and to find out which variables were associated with a higher absolute prediction error.

Results Children less than 12 months of age experienced higher myopic shifts and a larger mean rate of refractive change per year compared with older children. We found higher myopic shifts in younger children at time of surgery and children with unilateral cataract. Absolute prediction error was significantly higher in Group A compared with Groups B and C $(p=0.022$ and $p=0.037$, respectively). Multiple regression analysis showed that corneal radius was the only variable significantly associated with absolute prediction error.

Conclusion Our data demonstrate the complexity in predicting the postoperative refraction in children under 1 year old and show that age at surgery and laterality are factors to consider when deciding which IOL power to implant in children.

\section{INTRODUCTION}

Due to advances in surgical techniques, improvements in intraocular lens (IOL) materials and better understanding of the growth of the eye, the acceptable age for IOL implantation in children and infants is becoming progressively younger. ${ }^{12}$

Although IOL implantation in children less than 2 years old is becoming an increasingly accepted procedure, some surgeons prefer to leave infants aphakic after cataract surgery and use contact lenses for optical correction. ${ }^{3}$ Previous studies showed aphakic eyes display a greater rate of refractive growth than pseudophakic eyes. ${ }^{4}$ Children with higher rate of refractive growth were found to have poorer long-term visual results. ${ }^{6}$ This supports the use of IOL implantation in children and infants.

Despite developments in IOL implantations in younger children, the choice of which implant power to use remains one of the most difficult and most discussed aspects in paediatric cataract surgery. Age at surgery, visual input, presence of an IOL, laterality and inter-ocular axial length difference have all demonstrated an affect on growth of the eye. ${ }^{7}$ This leads to complicated IOL power predictions in an individual child. Surgeons have varying opinions as to the optimal postoperative refractive goal in infants and children. Currently most surgeons 'underpower' the lens, resulting in a hyperopia in the years following implantation. ${ }^{9} 10$ Some authors advise aiming for emmetropia postoperatively. This option does not allow for postoperative myopic shift, but may allow for easier management of amblyopia in the early postoperative period. ${ }^{3}$

There is still no consensus on the ideal postoperative refraction in infants and children after IOL implantation. In this study, we analysed myopic shift and prediction error in children operated in the Erasmus University Hospital, Rotterdam, The Netherlands.

\section{METHODS}

The medical records of 82 consecutive paediatric patients who had undergone cataract surgery at our clinic between January 2000 and January 2009 were reviewed retrospectively. Both congenital and developmental, and unilateral and bilateral cataract were included. Excluded patients were those with intra-ocular congenital anomalies such as persistent fetal vasculature $(n=4)$, patients without IOL implantation $(n=25)$ and those with a follow-up examination less than 3 months postoperatively $(n=3)$. Four patients were lost to follow-up. Patients were divided into three groups based on age at surgery regardless of whether the cataract(s) were unilateral or bilateral: Group A, 0-1 years old; Group B, 1-7 years old; Group C, 7-18 years old.

Preoperative evaluation included slit-lamp examination, dilated funduscopy, retinoscopy, keratometry and biometry. Axial length measurements were performed using the Alcon Ocuscan (Alcon, Irvine, California, USA).. Keratometry readings were obtained in the operating room on sedated children in supine position with automatic hand-held keratometer (Righton Retinomax K-Plus2; Righton, Tokyo, Japan). The SRK-T and Holladay II formulas were used to calculate IOL power, which was adjusted for age and expected myopic shift of the child. We used the Holladay IOL Consultant \& Surgical Outcome Assessment Software package (Holladay Consulting, Bellaire, Texas, USA) to calculate lens power. In unilateral cataract cases, the refractive error of the fellow eye was taken into account when deciding what power to implant in order to prevent significant anisometropia.

Phacoemulsification was performed according to a standard protocol. In brief, a $3.0 \mathrm{~mm}$ corneoscleral incision was made. A circular capsulorhexis was created followed by hydrodissection. Lens contents were aspirated and the IOL was placed in the capsular bag. All wounds were closed with 10-0 ethilon sutures. Primary posterior capsulorhexis or 
capsulotomy was performed depending on the age of the child. An anterior vitrectomy was performed when necessary. During the first cases of cataract surgery with IOL implantation, polymethyl methacrylate (PMMA) intra-ocular lenses were implanted; later cases received foldable silicone or acrylic intra-ocular lenses. Postoperatively, all children received dexamethasone $0.1 \%$ eye drops three times a day for 4-6 weeks. All children received stringent amblyopia treatment (occlusion) and adequate optical correction with contact lenses or spectacles when necessary.

\section{Data collection}

The target refraction (desired postoperative refractive error) and the IOL calculation formula were both selected by the operating surgeon. Generally, the younger the patient at time of surgery, the more hyperopic the target refractive error was chosen to anticipate for the myopic shift. All children were reviewed 1 day, 1 week and 4 weeks postoperatively; further check-ups were based on individual patient needs. Refraction at 3 months after surgery was used as the postoperative refraction (when the corneoscleral incision was stable). The spherical equivalent of the postoperative refractive error was used in the analyses (spherical equivalent: spherical power $+(1 / 2 \times$ cylindrical power)). Using target refraction, prediction error for each surgical outcome was calculated with the following formula $^{11}{ }^{12}$ : prediction error $(D)=$ desired postoperative refraction (D)-actual postoperative refraction (D).

\section{Statistics}

The Mann-Whitney $U$ test was used to analyse differences in prediction errors between groups (A, B and C), differences in prediction error in axial length ( $<22$ and $\geq 22 \mathrm{~mm}$ group), corneal radius ( $<7.5$ and $\geq 7.5 \mathrm{~mm}$ group) and myopic shift $(<-1$ and $\geq-1 \mathrm{D}$ group). Multiple regression analysis was used to analyse whether the prediction error was affected by age at time of IOL implant, axial length, surgeon, IOL power and corneal radius. Residual plots were inspected for possible violation of model assumptions of normality and homogeneity of variance for error terms. Differences in lens calculation error between the SRK-T and Holladay II formulas were analysed using the Wilcoxon signed-rank test. The Mann-Whitney U test was used to compare the absolute lens calculation error and rate of change per year in subgroups. Analyses were performed using the statistical software package SPSS 15 for Windows (SPSS Inc., Chicago, IL, USA).

\section{RESULTS}

\section{Patient demographics}

We reviewed 70 eyes of 46 children. The children's demographics are displayed in table 1 . The younger children in groups $A$ and $B$ had more congenital cataract than group $C$. Older children in groups $\mathrm{B}$ and $\mathrm{C}$ had more developmental cataract than group $\mathrm{A}$.

The traumatic cataracts in groups $\mathrm{B}$ and $\mathrm{C}$ were caused by firework accidents. In group $\mathrm{C}$, three children had radiotherapyinduced cataract. In those cases radiotherapy was used as medical treatment for a case of rhabdomyosarcoma, a cerebellar medulloblastoma and an acute lymphoblastic leukaemia. In one of the patients in group B, juvenile idiopathic arthritis based uveitis was the cause of the cataract. The secondary cataract in group $C$ was caused by the use of corticosteroids for Wegener's disease.

\section{Myopic shift and target refraction}

Figure 1 shows a logarithmic relationship between patient age at time of cataract surgery and refractive change spherical
Table 1 Patient characteristics ( $\mathrm{N}=70$ eyes)

\begin{tabular}{|c|c|c|c|c|}
\hline Group & $\begin{array}{l}\text { Eyes/ } \\
\text { patients } \\
(\mathbf{n} / \mathbf{n})\end{array}$ & $\begin{array}{l}\text { Bilateral/ } \\
\text { unilateral } \\
(\mathbf{n} / \mathbf{n})\end{array}$ & $\begin{array}{l}\text { Male/ } \\
\text { female } \\
(\mathbf{n} / \mathbf{n})\end{array}$ & Type of cataract \\
\hline Group A: $0-12$ months old & $10 / 8$ & $2 / 6$ & $4 / 4$ & 8 congenital \\
\hline Group B: $1-7$ years old & $42 / 26$ & $16 / 10$ & $15 / 11$ & $\begin{array}{l}11 \text { congenital } \\
13 \text { developmental } \\
1 \text { traumatic } \\
1 \text { inflammatory }\end{array}$ \\
\hline Group C: $7-18$ years old & $18 / 12$ & $6 / 6$ & $7 / 5$ & $\begin{array}{l}4 \text { congenital } \\
3 \text { developmental } \\
1 \text { traumatic } \\
3 \text { after radiation therapy } \\
1 \text { secondary }\end{array}$ \\
\hline Total patients & $70 / 46$ & $24 / 22$ & $26 / 20$ & $\begin{array}{l}23 \text { congenital } \\
16 \text { developmental } \\
7 \text { other }\end{array}$ \\
\hline
\end{tabular}

equivalent observed during the follow-up period (mean followup period 28.6 months). Group $\mathrm{C}$ had a significantly lower rate of change per year than group $A(p=0.001)$ and group $B$ $(p=0.002)$. Patients who underwent a unilateral phacoemulsification had a significantly higher rate of change per year than patients who underwent bilateral phacoemulsification $(-0.61 \mathrm{vs}$ $-0.29 \mathrm{D} /$ year; $\mathrm{p}=0.045)$. Multiple regression analyses yielded the following equation to predict myopisation:

Amount of myopisation $(\mathrm{D})=-7.97+0.05 \times$ age at surgery

$$
+0.97 \times \text { bilaterality }(\mathrm{p}=0.0001) \text {. }
$$

Variables age at time of surgery and laterality were both statistically significant ( $p=0.005$ and $p=0.024$, respectively). This equation showed higher expected myopic shifts in younger children at time of surgery and children with unilateral cataract (table 2).

\section{Prediction error}

The absolute prediction error was significantly higher in group A than in groups $B(p=0.022)$ and $C(p=0.037$; table 3$)$. Table 4 shows the prediction error data in subgroups used for statistical analysis based on biometric analysis. Prediction error was significantly greater in eyes with axial length $<22 \mathrm{~mm}$ and in

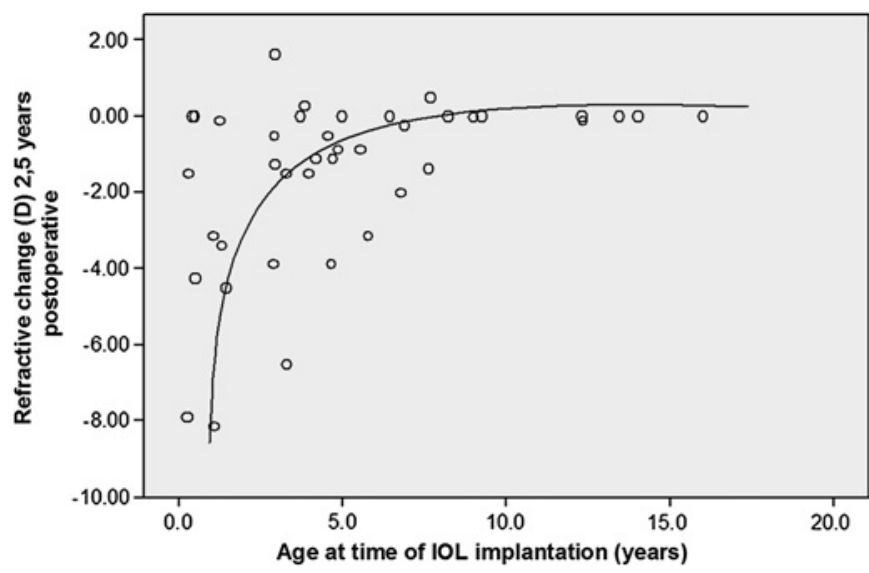

Figure 1 Relationship between age at time of intraocular lens (IOL) implantation and refractive change. 
Table 2 Calculated postoperative refractive goal according to age and laterality

\begin{tabular}{lll}
\hline & \multicolumn{2}{l}{$\begin{array}{l}\text { Underpowering intra-ocular lens } \\
\text { (D) }\end{array}$} \\
\cline { 2 - 3 } Age (months) & Unilateral & Bilateral \\
\hline 3 & 7.8 & 6.9 \\
6 & 7.7 & 6.7 \\
12 & 7.4 & 6.4 \\
24 & 6.8 & 5.8 \\
48 & 5.6 & 4.6 \\
\hline
\end{tabular}

eyes with corneal radii $<7.5 \mathrm{~mm}$ ( $p=0.005$ and $p=0.009$, respectively). We found no significant differences in prediction error between the two myopic shift groups $(p=0.42)$.

We analysed the effect of axial length on prediction error after adjustment for age at time of surgery and corneal radius and found no significant association $(\mathrm{p}=0.761)$. We adjusted for age and corneal radius because, on average, younger children have smaller axial lengths and steeper keratometry values than older children. $^{3} 13$ The effect of age on absolute prediction error was not significant after adjusting for axial length and corneal radius $(\mathrm{p}=0.899)$. Corneal radius showed a significant effect on absolute prediction error and showed no alterations in significance after adjusting for age and axial length $(p=0.022)$. IOL power and surgeon were not significantly associated with prediction error ( $p=0.068$ and $p=0.619$, respectively).

\section{DISCUSSION}

\section{Myopic shift and target refraction}

The normal growth of children's eyes has been demonstrated to be a complex interaction between axial length, lens growth and changes in corneal curvature in an attempt to maintain emmetropia. ${ }^{14}$ Axial length growth occurs mainly in the first 2 years of life, increasing from an average of $16.8 \mathrm{~mm}$ at birth to $23.6 \mathrm{~mm}$ in adulthood. ${ }^{3} 15$ Changes in corneal curvature occur almost entirely within the first 6 months of life, decreasing from a mean power of 51.2 to $43.5 \mathrm{D} .{ }^{16}$ Lens power decreases nearly $10 \mathrm{D}$ in the first year of life. ${ }^{14}$ We found a similar logarithmic relationship in myopic shift with age in our group of pseudophakic children, with more myopic shift occurring in children operated at a younger age, compared with previous studies. 91017

Data on refractive changes in pseudophakic children with long-term follow-up is rare. Although it has been suggested that IOL implantation may alter axial elongation, most authors have found an overall myopic shift, greatest in the younger children and continuing until the age of 20 years. ${ }^{3} 5$ McClatchey and Parks demonstrated greater myopic shifts in children aged 2 years and younger at time of surgery. They also found a greater variance in the predicted refractive change compared with those $>2$ years old at time of IOL implantation. ${ }^{18}$ Our data are compatible with these findings, showing larger myopic shift and wider ranges in target refraction under the age of 7 years, and more so under the age of 1 year. We feel that this can be explained by the fact that in pseudophakic eyes the lens power is static, so that increase in axial length results in a decrease in hyperopia or an increase in myopia. ${ }^{3}$ The effect of vertex distance is another optical phenomenon that influences the changes in refraction in growing pseudophakic eyes. As the eye grows, the IOL moves farther from the retina, causing a myopic shift. $^{5}$

A greater myopic shift in children with unilateral pseudophakia versus children with bilateral pseudophakia has already been documented. ${ }^{18}$ Our results confirmed these findings, as we also found a significantly greater rate of change in the unilateral group than in the bilateral group. Poorer quality of the retinal image in unilateral cataract cases and deprivation amblyopia could be a trigger for accelerated growth in the affected eye. This would be explained by a decrease in retinal proteoglycan synthesis that leads to an increased rate of scleral growth in these patients. ${ }^{19}$

At the moment there is no agreement in the literature on the ideal target refraction in infants and children after IOL implantation. A majority of surgeons choose to underpower the IOL, resulting in hyperopia, in anticipation of the myopic shift in the years after surgery. ${ }^{20} 21$ Enyedi et al suggested underpowering by $+6 \mathrm{D}$ at 1 year of age and decreasing $1 \mathrm{D}$ per year, up to $-1 \mathrm{D}$ at 8 years and older. ${ }^{17}$ Astle et al supported these recommendations except for that they recommended underpowering the IOL by as much as 7.0-8.0 D at age $1-2$ years and $5.0-7.0 \mathrm{D}$ at age $2-4$ years. ${ }^{10}$

We found a wide variation in myopic shifts $(-8.13$ to $0 \mathrm{D})$ among our patients less than 1 year of age. Both laterality and age at time of IOL influenced the myopic shift, comparable with previous findings. ${ }^{1} 9$ Hence, we recommend underpowering more in younger children than older children and almost $+1 \mathrm{D}$ more in unilateral cases than bilateral cases. According to the expected myopisation formula yielded by multiple regression analysis, we recommend underpowering by $+7.8 \mathrm{D}$ in children with unilateral cataract at age of 3 months at time of IOL implantation.

\section{Prediction error}

The mean absolute prediction error found in our patient group was 1.14 (range $0.01-3.53$ ) D. This is comparable to the prediction error in previous studies in children, varying from 1.08 to $1.16 \mathrm{D}^{12}{ }^{22}$ Although the absolute prediction error in our study was not higher than findings in research based on children, it remains much higher than that found in adults. For comparison, in a study by Olsen using the latest generation IOL power calculation formulas the mean prediction error was $0.47 \mathrm{D}^{23}$ There are several possible reasons for the higher prediction error observed in children. Most importantly, the measurement of axial length and keratometry in infants is usually done under general anaesthesia in an eye that is unable to cooperate with precise fixation and centration. ${ }^{3}$ In addition, the desired residual hyperopia necessary to compensate for the myopic shift causes a higher prediction error. Furthermore, axial lens positions based

Table 3 Results by age

\begin{tabular}{|c|c|c|c|c|c|c|}
\hline Age & $\begin{array}{l}\text { Target } \\
\text { refraction (D) }\end{array}$ & $\begin{array}{l}\text { Implant } \\
\text { power (D) }\end{array}$ & $\begin{array}{l}\text { Absolute prediction } \\
\text { error }\end{array}$ & $\begin{array}{l}\text { Follow-up } \\
\text { (years) }\end{array}$ & $\begin{array}{l}\text { Change (D) at last } \\
\text { follow-up }\end{array}$ & $\begin{array}{l}\text { Rate of change } \\
\text { (D/year) }\end{array}$ \\
\hline Group A: $0-12$ months old & $+3.70(+0.49$ to +8.5$)$ & $+26.9(20-30)$ & 2.09 (0.95 to 3.53$)$ & 3.0 & $-3.18(-8.13$ to 0.0$)$ & -1.05 \\
\hline Group C: $7-18$ years old & $+0.06(-0.78$ to +1.53$)$ & $+20.39(8-29)$ & $0.88(0.01-2.90)$ & 1.3 & $-0.06(-1.38$ to +0.5$)$ & -0.05 \\
\hline
\end{tabular}


Table 4 Absolute prediction errors

\begin{tabular}{ll}
\hline Subgroup & $\begin{array}{l}\text { Absolute prediction error } \\
\text { (mean } \pm \text { SE (range)) (D) }\end{array}$ \\
\hline Axial length $<22 \mathrm{~mm}$ & $1.6 \pm 0.24(0.10-3.53)$ \\
Axial length $\geq 22 \mathrm{~mm}$ & $0.85 \pm 0.20(0.01-0.30)$ \\
Corneal radii $<7.5 \mathrm{~mm}$ & $2.03 \pm 0.32(0.95-3.30)$ \\
Corneal radii $\geq 7.5 \mathrm{~mm}$ & $1.08 \pm 0.18(0.01-3.53)$ \\
Myopic shift $\geq-1 \mathrm{D}$ & $1.06 \pm 0.18(0.01-3.30)$ \\
Myopic shift $<-1 \mathrm{D}$ & $1.40 \pm 0.32(0.01-3.53)$ \\
\hline
\end{tabular}

on anterior chamber depths have been obtained from studies in adult populations. These data might not apply to the shallower anterior chambers in paediatric eyes. ${ }^{24}$

Our multiple regression model showed that only corneal radius was significantly associated with prediction error; age at time of surgery, axial length, surgeon, IOL power and laterality did not appear to play a role. Greater prediction errors in eyes with smaller corneal radii have also been found in previous literature. Moore et al showed that age at time of surgery and corneal radius were the only two variables significantly associated with mean absolute prediction error. ${ }^{22}$ Tromans et al found greater prediction errors in 12 eyes with corneal radii $<7.3 \mathrm{~mm}$, but this was not statistically significant, possibly due to the small number of patients included. ${ }^{11}$ In paediatric cases keratometry values are usually obtained under general anaesthesia, possibly inducing centration problems. When the calculation of corneal power is inaccurate, it will induce profound consequences on the calculation of the IOL power and the subsequent postoperative refraction. ${ }^{23}$ The accuracy of keratometry measurements on sedated paediatric patients in supine position is doubtful; Mittelviefhaus and Gentner found that fixation problems during keratometry measurements in children could lead to less accurate keratometry readings. ${ }^{25}$ However, there is not much documentation on this important section of paediatric IOL calculation.

\section{Limitations}

Due to the retrospective design of this study we were unable to retrieve the refractive outcomes and biometry values of all of the subjects. In addition, the size of our patient group and the nonstandardisation of patient selection and surgical techniques could have had some influence on the investigated outcomes.

\section{CONCLUSION}

As IOL implantation becomes more common in young children, it is necessary that surgeons have the ability to predict postoperative refraction as accurately as possible and choose the best IOL power for each individual child. We found that the age at time of surgery and laterality are important variables in predicting myopic shift. Hence, we recommend a more hyperopic target refraction for younger children and children with unilateral cataracts. Our data from 70 consecutive paediatric IOL implantations show that corneal power is an important variable in predicting the postoperative refraction. The steeper corneas in younger children play an important role in the higher prediction errors in this particular group. It would be helpful to investigate further the accuracy in keratometry readings in these younger children.

\section{Competing interests None.}

Ethics approval This study was conducted with the approval of the Ethics Committee Erasmus MC University Hospital.

Provenance and peer review Not commissioned; externally peer reviewed.

\section{REFERENCES}

1. Gouws $\mathbf{P}$, Hussin HM, Markham RH. Long term results of primary posterior chamber intraocular lens implantation for congenital cataract in the first year of life. Br J Ophthalmol 2006;90:975-8.

2. Lambert SR, Lynn M, Drews-Botsch C, et al. Intraocular lens implantation during infancy: perceptions of parents and the American Association for Pediatric Ophthalmology and Strabismus members. J AAPOS 2003;7:400-5.

3. Eibschitz-Tsimhoni M, Archer SM, Del Monte MA. Intraocular lens power calculation in children. Surv Ophthalmol 2007;52:474-82.

4. Superstein R, Archer SM, Del Monte MA. Minimal myopic shift in pseudophakic versus aphakic pediatric cataract patients. J AAPOS 2002 0ct;6:271-6.

5. McClatchey SK, Dahan E, Maselli E, et al. A comparison of the rate of refractive growth in pediatric aphakic and pseudophakic eyes. Ophthalmology 2000;107:118-22.

6. Weakley DR, Birch E, McClatchey SK, et al. The association between myopic shift and visual acuity outcome in pediatric aphakia. J AAPOS 2003;7:86-90.

7. Lal G, Trivedi $\mathrm{RH}$, Wilson ME Jr, et al. Interocular axial length difference in eyes with pediatric cataracts. J AAPOS 2005;9:358-62.

8. Vasavada AR, Raj SM, Nihalani B. Rate of axial growth after congenital cataract surgery. Am J Ophthalmol 2004;138:915-24.

9. Plager DA, Kipfer H, Sprunger DT, et al. Refractive change in pediatric pseudophakia: 6-year follow-up. J Cataract Refract Surg 2002 May;28:810-15.

10. Astle WF, Ingram AD, Isaza GM, et al. Paediatric pseudophakia: analysis of intraocular lens power and myopic shift. Clin Experiment Ophthalmol 2007; 35:244-51.

11. Tromans C, Haigh PM, Biswas $S$, et al. Accuracy of intraocular lens power calculation in paediatric cataract surgery. Br J Ophthalmol 2001;85:939-41.

12. Neely DE, Plager DA, Borger SM, et al. Accuracy of intraocular lens calculations in infants and children undergoing cataract surgery. J AAPOS 2005;9:160-5.

13. Trivedi Rhew M. Keratometry in pediatric eyes with cataract. Arch Opthalmol 2008;126:38-42.

14. Gordon RA, Donzis PB. Refractive development of the human eye. Arch Ophthalmo 1985; 103:785-9.

15. McClatchey SK, Hofmeister EM. Intraocular lens power calculation for children. In: Wilson ME, Trivedi RH, Pandey SK, eds. Pediatric cataract surgery: techniques, complications, and management. Philadelphia: Lippincot Williams \& Wilkins, 2005:30-7.

16. Inagaki Y. The rapid change of corneal curvature in the neonatal period and infancy. Arch Ophthalmol 1986;104:1026-7.

17. Enyedi LB, Peterseim MW, Freedman SF, et al. Refractive changes after pediatric intraocular lens implantation. Am J Ophthalmol 1998;126:772-81.

18. McClatchey SK, Parks MM. Theoretic refractive changes after lens implantation in childhood. Ophthalmology 1997;104:1744-51.

19. Hung GK, Ciuffreda KJ. Incremental retinal-defocus theory of myopia development schematic analysis and computer simulation. Comput Biol Med 2007;37:930-46.

20. McClatchey SK, Parks MM. Myopic shift after cataract removal in childhood. J Pediatr Ophthalmol Strabismus 1997;34:88-95.

21. Crouch ER, Crouch ER Jr, Pressman SH. Prospective analysis of pediatric pseudophakia: myopic shift and postoperative outcomes. J AAPOS 2002;6:277-82.

22. Moore DB, Ben Zion I, Neely DE, et al. Accuracy of biometry in pediatric catarac extraction with primary intraocular lens implantation. J Cataract Refract Surg 2008;34:1940-7.

23. Olsen T. Calculation of intraocular lens power: a review. Acta Ophthalmol Scand 2007:85:472-85

24. Holladay JT. Standardizing constants for ultrasonic biometry, keratometry, and intraocular lens power calculations. J Cataract Refract Surg 1997;23:1356-70.

25. Mittelviefhaus H, Gentner C. Messungenauigkeiten der Keratometrie bei der Intraokularlinsenberechnung fur Sauglinge[Errors in keratometry for intraocular lens implantation in infants]. Ophthalmologe 2000;97:186-8. 